Accepted version of

Coelho, G. L. H., Vilar, R., Hanel, P. H. P., Monteiro, R. P., Ribeiro, M. G. C., \& Gouveia, V. V. (2018). Optimism Scale: evidence of psychometric validity in two countries and correlations with personality. Personality and Individual Differences.

\title{
Optimism Scale: Evidence of Psychometric Validity in Two Countries and Correlations with Personality
}

Gabriel Lins de Holanda Coelho, Cardiff University, United Kingdom Roosevelt Vilar, Massey University, New Zealand Paul H. P. Hanel, University of Bath, United Kingdom Renan Pereira Monteiro, Federal University of Mato Grosso, Brazil Maria Gabriela Costa Ribeiro, Federal University of Paraíba, Brazil Valdiney Veloso Gouveia, Federal University of Paraíba, Brazil

Correspondence to: Valdiney V. Gouveia, Departamento de Psicologia, Universidade Federal da Paraíba, 58.051-900 Joao Pessoa, PB, Brazil.

E-mail contact: linshc@gmail.com (Gabriel Coelho), roosevelt.vilar@gmail.com (Roosevelt Vilar) 
Abstract: Optimism can be defined as the hope that something good is going to happen in the future. It is a relevant construct in the study of happiness, and is associated with a range of variables, including subjective well-being, reduced risk of suicidal ideation, quality of social relationships, and a healthier lifestyle. However, current measures of optimism were criticized regarding their structure and reliability. To address these limitations, Pedrosa et al. (2015) proposed a new scale of dispositional optimism that was originally published in Spanish. In the present research, we aimed to provide further psychometric evidence of the 9-item Optimism Scale in the United Kingdom ( $N$ $=325)$ and Brazil $(N=421)$. Exploratory and confirmatory factor analyses in both countries were consistent with the original findings, supporting the unifactorial structure. Item Response Theory revealed good discrimination, level of difficulty, and informativeness of the items. Further, we found good reliability estimates of the scale, full factorial invariance across participants' gender and partial invariance across countries, and positive correlations with all Big-5 personality traits. In sum, our findings suggest that the dispositional Optimism Scale is a psychometrically adequate measure that can be used cross-culturally.

Keywords: Dispositional optimism; validation; psychometric properties; cross-cultural; personality. 
"You can try the best you can, The best you can is good enough."

\section{Introduction}

Radiohead - Optimistic

Optimism plays an important role across many areas in our lives, such as in educational, organizational, and health-related contexts. For instance, optimism is an essential characteristic for leaders, because being optimistic allows them to inspire people, to see opportunities even in adverse situations, and to lead people to a better future (Gallo, 2011). More specifically, optimistic politicians are perceived as more appealing to voters (Malhotra \& Margalit, 2014), and school teachers who are optimistic about the future of their students help them to obtain higher academic achievements (Kirby \& DiPaola, 2011). Further, a meta-analysis conducted across 83 countries found that optimism was positively associated with a range of physical health variables, including lower pain and diseases outcomes such as cancer or cardiovascular outcomes (Rasmussen, Scheier, \& Greenhouse, 2009).

Optimism is defined as the hope that something good is going to happen in the future (Carver, Scheier, \& Segerstrom, 2010). It can be characterized as a cognitive construct, but with emotional overtones (whether expecting good or bad things to happen) and motivational implications (levels of expectation; Carver \& Scheier, 2014). It is therefore not surprising that optimism is a key variable in positive psychology - the sub-field of psychology that studies virtuous aspects, psychological strengths, and positive emotions in our lives (Snyder, Lopez, \& Pedrotti, 2010).

To study optimism, it is essential to measure it in a reliable and valid way. However, as we outline below, previous measures of optimism were criticized for various reasons, indicating the need for an improved and well-validated scale to measure optimism. To fill this gap, the present research aimed to validate a recently 
developed measure of dispositional optimism (Pedrosa et al., 2015) in the United Kingdom and Brazil to provide further evidence of the structure and validity of the scale.

\section{Explanatory and Dispositional Optimism}

The literature differentiates between explanatory and dispositional optimism. The first relies on explanations of events, such as the way people explain the occurrences of good or bad situations in everyday life, including positive thoughts and the interpretation of the causes of negative situations (Bastianello \& Hutz, 2015; Peterson \& Steen, 2009). For example, when getting good grades at school, students can see them as a reward for their effort and assume they will get even better grades in the future. On the other hand, the core of dispositional optimism is composed of expectations about future events. In this case, the focus is on the projection of how well the student would do in the next year. These expectations have different intensity levels and are modifiable during life, are specific, and occur because of a lack of certainty or conviction regarding future events (Bastianello \& Hutz, 2015).

Dispositional optimism originates from the expectancy-value model of motivation (Carver et al., 2010), and it is the focus in the present research, offering beneficial links with a range of attitudes and behaviors. Research has found positive associations between dispositional optimism and healthier lifestyle and dietary habits (Giltay, Geleijnse, Zitman, Buijsse, \& Kromhout, 2007), greater career success and better social relations (Carver \& Scheier, 2014), reduced risk of suicidal ideation (Hirsch, Wolford, LaLonde, Brunk, \& Morris, 2007), and subjective well-being (He, Cao, Feng, Guan, \& Peng, 2013). 


\section{How to Measure Optimism?}

When assessing dispositional optimism, however, it is still unclear if the construct is unidimensional and bipolar - with pessimism on one end and optimism on another - , or if it has two dimensions. That is, whether optimism and pessimism form two separate, but correlated dimensions. Carver and Scheier (2003) considered dispositional optimism as a one-dimensional construct ranging from pessimism to optimism. This unidimensional view of optimism-pessimism was supported across a range of studies (e.g., Chiesi, Galli, Primi, Innocenti Borgi, \& Bonacchi, 2013; Segerstrom, Evans, \& Eisenlohr-Moul, 2011). In contrast, others have argued that optimism and pessimism are empirically different, albeit correlated, and should therefore be measured separately to avoid losing information (Marshall, Wortman, Kusulas, Hervig, \& Vickers, 1992). Further studies supported the separate factor structure (Chang, D’Zurilla, \& Maydeu-Olivares, 1994; Glaesmer et al., 2012; Herzberg, Glaesmer, \& Hoyer, 2006; Kubzansky, Kubzansky, \& Maselko, 2004).

Two of the most influential measures of optimism are the Life Orientation Test (LOT; Scheier \& Carver, 1985), and its successor, the Life Orientation Test-Revised (LOT-R; Scheier, Carver, \& Bridges, 1994). These measures were developed to assess individual differences regarding optimism versus pessimism, following the onedimensional continuum approach described above. They were validated across different contexts and languages (e.g., Jovanović \& Gavrilov-Jerković, 2013; Monzani, Steca, \& Greco, 2014; Perczek, Carver, Price, \& Pozo-Kaderman, 2000; Schou, Ekeberg, Ruland, Sandvik, \& Kåresen, 2004).

However, some limitations of the LOT and LOT-R became salient over the years, such as the unidimensional structure and low internal consistency. Although several studies provided evidence for the unidimensional structure (e.g., Carver, \& 
Bridges, 1994; Monzani et al., 2014), other studies suggested a two-factors structure (cf. Batianello \& Hutz, 2015). This two-factor structure was further empirically supported (Gaspar, Ribeiro, Matos, Leal, \& Ferreira, 2009; Reilley, Geers, Lindsay, Deronde, \& Dember, 2005). Indeed, in some situations, separating optimism-pessimism led to better prediction of outcome variables, such as dimensions of mood and personality, and psychological and physical health (e.g., Marshall et al., 1992; Robinson-Whelen, Kim, MacCallum, \& Kiecolt-Glaser, 1997).

Another limitation of the LOT and LOT-R is the low internal consistencies found in many samples. For example, the reliability levels estimated through Cronbach's alpha ranged between .63 and .68 in some studies (Bandeira, Bekou, Lott, Teixeira, \& Rocha, 2002; Glaesmer et al., 2012; Herzberg et al., 2006; Jovanović \& Gavrilov-Jerković, 2013; Vera-Villarroel et al., 2017) - a borderline acceptable range (e.g., $\alpha$ between .60 and .70; Kline, 2013).

Despite these limitations of the structure and reliability of the LOT and LOT-R, it is important to highlight that both measures are very popular to measure optimism. They have been used across the world with overall satisfactory results that are in line with theoretical predictions (e.g., Monzani et al., 2014; Perczek et al., 2000, Schou et al., 2004). Thus, the present research did not aim to discredit the measures, but instead hopes to introduce an alternative scale of dispositional optimism - which might help to expand our knowledge on the topic. To achieve this aim, the present research sought to validate the Optimism Scale across two countries (United Kingdom and Brazil), using a range of stringent psychometric methods. The measure was proposed by Pedrosa and colleagues (2015), with a unidimensional structure that focuses only on the positive aspects of optimism. 


\section{Optimism Scale}

The initial 10-item Optimism Scale was validated in a sample of 2.693 participants from Spain (Pedrosa et al., 2015). The sample was divided to assess the structure of the scale across methods, such as exploratory factor analysis and confirmatory factor analysis. One item was excluded from the analysis because it loaded too low on the main optimism factor, leaving nine items that formed a unidimensional structure with a good internal consistency ( $\alpha=.84$; Kline, 2013). Item Response Theory revealed that all items presented high to very high discrimination levels (Baker, 2001).

To test its convergent validity, the scale was correlated with the Overall Personality Assessment Scale that measures the Big-5 (Vigil-Colet, Morales-Vives, Camps, Tous, \& Lorenzo-Seva, 2013) and the Trait Meta-Mood Scale (emotional intelligence; Fernández-Berrocal, Extremera, \& Ramos, 2004). Results showed significant correlations of dispositional optimism with all five big factors: emotional stability (i.e., neuroticism [negative], $r=.62, p<.001)$, extroversion $(r=.31, p<.001)$, conscientiousness $(r=.33, p<.001)$, openness to change $(r=.15, p<.001)$, and agreeableness $(r=.26 ; p<.001)$. Also, the construct was positively correlated with both emotional intelligence dimensions: emotional clearness $(r=.34, p<.001)$ and emotional repair $(r=.62, p<.001)$. As the Optimism Scale was only published recently in Spanish, we found just one study that used this scale: Optimism was positively related with perception of health and positive affect (Vera-Villarroel et al., 2017).

\section{The Present Research}

Given the importance of dispositional optimism in predicting a range of important psychological outcomes such as emotional stability, socialization, and career success, we aimed to contribute to the literature by validating the Optimism Scale in English and Portuguese, with samples from the United Kingdom and Brazil. Further, 
while Pedrosa et al. (2015) mainly relied on students as participants, we aimed to extend their findings to other populations (general public and convenience sample). Overall, we hoped to show that the Optimism Scale is a reliable and cross-cultural validated alternative measure of dispositional optimism. Also, as the Optimism Scale was only recently published (2015), it is crucial to test its psychometric properties in different cultures before it can be used in wider research.

We followed the same analytical approach of Pedrosa and colleagues (2015) by dividing our samples into two groups, to separately perform the exploratory and confirmatory factor analysis. We also used Item Response Theory to further assess the psychometric properties of the Optimism Scale, and correlated the scale with the Big-5 personality dimensions. Additionally, extending Pedrosa et al.'s work, we tested for measurement invariance across countries and gender.

\section{Method}

\section{Participants and Procedure}

The British sample consisted of 325 participants $\left(M_{\text {age }}=36.84, S D=12.20\right.$, 53.2\% women). Participants were recruited on Prolific Academic and participated in exchange for a monetary compensation. The Brazilian sample consisted of 421 respondents $\left(M_{\mathrm{age}}=23.98, S D=6.49 ; 58.2 \%\right.$ women $)$. Participants completed an online questionnaire, which was advertised in social networks. The average completion time was 5 minutes. The datasets of both studies can be found on https://goo.gl/tuUNfm.

\section{Measures}

Optimism Scale (Pedrosa et al., 2015). This nine-items scale assesses dispositional optimism with items such as "When I think about the future, I am positive”. Responses were given on a 5-point scale, ranging from 1 (Strongly Disagree; to 5 (Strongly Agree). 
Ten-Item Personality Inventory (TIPI; Gosling, Rentfrow, \& Swann Jr., 2003). The TIPI measures the five big factors of personality through 10 items. Participants were asked to which extent they would describe themselves, as, for example, "critical, quarrelsome" or "extraverted, enthusiastic" on a 7-point scale, ranging from 1 (Disagree Strongly) to 7 (Agree Strongly). The measure was designed to measure five broad dimensions with only two items. Therefore, reliabilities were expected to be low. Nevertheless, other psychometric qualities such as convergent validity or test-retest reliabilities were found to be good (Gosling et al., 2003).

\section{Data Analysis}

All data were analyzed using the statistical programs Factor (Lorenzo-Seva \& Ferrando, 2013) and $R$ (R Development Core Team, 2015). First, to assess the structure of the measure, the samples were randomly divided into two equally sized groups, for the exploratory factor analysis (EFA; $U K, n=162$; Brazil, $n=210$ ), and confirmatory factor analysis (CFA; $U K, n=163 ;$ Brazil, $n=211$ ). The number of factors in an initial EFA was determined by the Hull method. This method is one of the most reliable approaches for determining the numbers of factors (Lorenzo-Seva, Timmerman, \& Kiers, 2011). Further, the Minimum Rank Factor Analysis (MRFA) was performed to test the scale's structure. For the CFA, the Robust Maximum Likelihood (MLR) estimator was used. The following cut-offs were considered for an acceptable fit (Hair, Black, Babin, \& Anderson, 2015; Tabachnick \& Fidell, 2013): (1) Chi-square $\left(\chi^{2}\right)$, which must be non-significant; (2) Comparative Fit Index (CFI) and (3) Tucker-Lewis Index (TLI), which are both recommended to be higher than .90; and (4) Standardized Root Mean Square Residual (SRMR), which must be lower than .10.

For the remaining analyses, we used the whole sample, again separately in each country. First, we assessed the discrimination, difficulty, and informativeness of the 
scale with the Multidimensional Item Response Theory (MIRT) package (Chalmers, 2012). Within the MIRT analysis, we used the Graded Response Model, because of the polytomous nature (more than two answer categories) of the measure (Samejima, 1968).

Next, we assessed whether the scale is invariant across countries and gender using Multigroup CFA (MLR method). Specifically, measurement invariance tests if participants across genders and countries answered the scale in the same way. Achieving measurement invariance allows meaningful cross-cultural and cross-gender comparisons (Davidov et al., 2014). For measurement invariance to be established, the goodness of fit indices such as CFI and SRMR of a more restricted model must be similar to a less restricted model (e.g., a model with constraint loadings and unconstraint loadings). Specifically, we relied on the guidelines that are commonly used in the literature (Chen, 2007; Cheung \& Rensvold, 2002): The change of the CFI must be $\leq .01$ and the change of the SRMR must be $\leq .03$.

Finally, we assessed the reliability and the convergent validity of the Optimism Scale. The reliabilities were assessed through McDonald's omega ( $\omega)$, Cronbach's alpha ( $\alpha$ ), and Composite Reliability (CR). Both $\omega$ and $\alpha$ should be above 70 (Kline, 2013), while the CR should be above .50 (Škerlavaj \& Dimovski, 2009). For the convergent validity, Pearson's $r$ correlations were calculated between optimism and the Big Five factors of personality, separately for each country.

\section{Results}

\section{Exploratory Factor Analysis}

We first performed an EFA with half of the data for each country separately, to test whether we would replicate the one-dimensional structure of the Optimism Scale (Pedrosa et al., 2015). Using the first half of the data, the Hull method of factor 
retention indicated a one-factor structure for both countries. Further, the Minimum Rank Factor Analysis indicated acceptable loadings for all items (above |.40|; see Table 1).

\section{[TABLE 1 AROUND HERE]}

\section{Confirmatory Factor Analysis}

To further confirm the one-factor structure, CFAs were performed for the second half of the data sets, again separately for each country. The following indicators were obtained using the MLR estimator: $\mathrm{UK}, \chi^{2}(27)=228.03, p<.001, \mathrm{CFI}=.868, \mathrm{TLI}=$ .824 , and SRMR $=.053$. The relatively poor fit improved after we allowed the errors from items 2 and 9, and 6 and 7 to correlate (Modification Indices $=68.22$ and 45.42), $\chi^{2}(25)=123.66, p<.001, \mathrm{CFI}=.935, \mathrm{TLI}=.907$, and SRMR $=.040$. For Brazil, the following indices were found: $\chi^{2}(27)=211.71, p<.001, \mathrm{CFI}=.831, \mathrm{TLI}=.774$, and $\mathrm{SRMR}=.056$. Once again, improvements were found after allowing the errors to correlate from items 6 and 7 (Modification Index $=128.40$ ), $\chi^{2}(26)=87.66, p<.000$, $\mathrm{CFI}=.944, \mathrm{TLI}=.922, \mathrm{SRMR}=.042$. All factorial weights (lambdas) were statistically different from zero in both countries $(\lambda \neq 0 ; z>1.96, p<.05)$.

\section{Item Response Theory}

Item discrimination and difficulty were assessed in the full samples, again separately for each country. The parameter labelled $a$ (Colum 1) in Table 2 shows item discrimination, which represents the ability of an item to discriminate between individuals varying in the latent trait. Higher values indicate items with higher discrimination (Baker, 2001). All items in the British sample are "very highly" discriminative $(a>1.7)$, whereas in the Brazilian sample, 5 items were "very highly" discriminative, 2 were "highly" ( $a$ between 1.35 and 1.69) and 2 items were "moderately" ( $a$ between 0.65 and 1.34).

[TABLE 2 AROUND HERE] 
The difficulties of the items are displayed as b1-b4 on Table 2. They estimate which level of the latent trait an individual needs to endorse to select the next higher response option (see Table 2). Items should neither be too easy nor too difficult (e.g., means across b's should be between 0 and $|1.5|$; Rauthmann, 2013). Results showed that all items were within the recommended range.

Item information curves (IIC; Figure 1) and Test information curves (TIC; Figure 2) were also assessed separately in both countries. The IIC tests how much information an item shares to the total information of the measure (Castro, Trentini, \& Riboldi, 2010). A higher $\mathrm{I}(\theta)$ indicates that an item is more informative. The TIC are based on the amount of information all items add to the total amount of information. The TIC is directly related to the reliability of the scale, with information of 10 being equivalent to a reliability of .90 (Cappelleri, Jason Lundy, \& Hays, 2014). Across both countries, item 9 was the most informative (Figure 1). Items with a moderate discrimination level in Brazil (see Table 2), also had a "flat" shape in their information curve, indicating only little information overall (items 1 and 4). However, those items showed acceptable values in all analysis (e.g., see discrimination, difficulty), and therefore were kept in the other analyses. For the test information curves, the results suggest a reasonable spread of discrimination across the latent range of optimism.

\section{[FIGURES 1 AND 2 AROUND HERE]}

\section{Reliabilities}

Reliabilities were assessed with McDonald's Omega, Cronbach's alpha, and Composite Reliability. The first two parameters indicated good internal consistency in both countries (UK, $\omega$ and $\alpha=.93$; Brazil, $\omega$ and $\alpha=.85$; Kline, 2013). Also, Composite Reliability was well above the .50 threshold (UK, .89; BR, .80; Škerlavaj \& Dimovski, 2009). 


\section{Measurement Invariance}

We considered three models (configural, metric, and scalar) to test for measurement invariance across gender and country. According to Milfont and Fischer (2010), if metric invariance is established, correlations can be meaningfully compared across countries. If scalar invariance is established, between-group comparisons of central tendency estimates (e.g., arithmetic mean) or of correlation coefficients are meaningful. Our results suggest that full invariance across gender was established, which allows us to make comparisons between women and men. Between countries however, only metric invariance was achieved. When we unconstrained the intercepts of items 4 and 8, $\triangle$ CFI was .008 and thus below the .01 threshold, indicating partial invariance.

\section{[TABLE 3 AROUND HERE]}

\section{Convergent Validity}

Convergent validity was assessed by correlating the Optimism Scale with the Big-5 personality traits, again separately for each country. The results showed positive and significant correlation of optimism with all traits, replicating Pedrosa et al.'s (2015) findings: Agreeableness (UK, $r=.21, p<.001$; Brazil, $r=.18, p<.001$ ), conscientiousness (UK, $r=.37, p<.001$; Brazil, $r=.24, p<.001$ ), emotional stability $(\mathrm{UK}, r=.54, p<.001$; Brazil, $r=.38, p<.001)$, extroversion $(\mathrm{UK}, r=.47, p<.001$; Brazil, $r=.19, p<.001$ ), and openness to experiences (UK, $r=.21, p<.001$; Brazil, $r$ $=.32, p<.001$ ). The correlations between optimism for the big one (all personality traits averaged together) were also significant and high (UK, $r=.63 ; p<.001 ;$ Brazil, $r$ $=.49, p<.001)$. 


\section{Discussion}

The aim of the present research was to provide psychometric evidence for the use of the Optimism Scale in English and Portuguese, using samples from the UK and Brazil. Results were consistent with the original findings (Pedrosa et al., 2015), suggesting a one factor structure composed of nine items. We found convergent validity with personality traits, good internal consistency, and full factorial invariance of the scale across participants' gender and partially across countries. These results corroborate the possibility of using the Optimism Scale in further studies.

First, the structure was assessed through exploratory and confirmatory factorial analysis. The EFA suggested, and the CFA confirmed, a one-factor structure in both countries, replicating Pedrosa et al.'s (2015) findings. Item Response Theory was used because of its capacity to provide detailed information about how well the items of a given instrument are precise across different ranges of the latent trait that is measured (Webster \& Jonason. 2013). Using Baker's guidelines to interpret the results (Baker, 2001), we found that for the British version of the optimism scale, items showed very high discrimination levels. In the Brazilian sample, the discrimination coefficients ranged between moderate to very high. In both countries, all items had the recommended level of difficulty (Rauthmann, 2013) and contributed considerably to the total informativeness of the measure. McDonald's omega, Cronbach's alpha, and Composite Reliability showed that the Optimism Scale is reliable (Kline, 2013; Škerlavaj \& Dimovski, 2009).

Further, we performed multigroup confirmatory factor analysis to test whether the scale is invariant across gender and countries. This test for measurement invariance was not performed in the original study in which the Optimism Scale was introduced to the literature (Pedrosa et al, 2015). Results showed that men and women responded 
similarly to the scale, allowing meaningful comparisons across gender. Cross-cultural comparisons revealed that full metric invariance was achieved, allowing meaningful comparisons across correlation coefficients. Scalar invariance was only partially achieved. However, if the number of items that are variant between countries is below $50 \%$, meaningful mean comparisons are still possible across the full scale (Vandenberg \& Lance, 2000).

In the literature, dispositional optimism refers to the expectations which individuals have of the future. These expectations are influenced by contextual factors and personality, among other variables. The strong associations of dispositional optimism with personality, especially emotional stability, has stirred a discussion of whether optimism is an independent personality trait or whether it is distinct (Carver \& Scheier, 2014). For example, Marshall et al. (1992) suggested that optimism depicts a combination of emotional stability and extroversion. However, further research showed that optimism can be reliably distinguished from the Big-5 (Alarcon, Bowling, \& Khazon, 2013; Kam \& Meyer, 2012). In our research, we found that individuals who are emotional stable, extroverted, agreeable, conscientious, and open to change are more likely to be optimistic and thus, tend to expect positive things for their future. However, especially the high correlations of dispositional optimism with emotional stability and extroversion beg the question to what extent optimism is distinct from personality. Thus, future research might want to assess the distinctiveness of dispositional optimism with more fine-grained measures of emotional stability and extroversion that measures each of the Big-5 dimensions with 6 facets (e.g., McCrae, Costa, \& Martin, 2010). For example, depression and self-consciousness - facets of emotional stability -, and positive emotions - a facet of extroversion - are presumably especially highly correlated with dispositional optimism. 


\section{Limitations, Future Studies, and Conclusion}

One potential limitation of our research is the use of convenience samples, which restrict the generalizability of the results. Indeed, previous research has found that it is often problematic to generalize from one sample type to others (Hanel \& Vione, 2016). Nevertheless, our findings are in line of those from Pedrosa et al. (2015) who have relied on a large sample of adolescents and young adults (14 to 23 years), suggesting that the sample type has little impact on the results. Another limitation is that responses might be biased because of social desirability, which is a common and known issue of self-report measures. However, it is unlikely that this was an issue here because data was collected anonymously online, thus reducing the effects of social desirability.

Future studies could focus on the temporal stability (test-retest) of the Optimism Scale and test for social desirability. Also, it is important to establish divergent validity of optimism to related constructs from positive psychology such as positivity, resilience, and flourishing, as well as applying the construct to different types of samples, such as employees and leaders from organizations or patients in hospitals. Also, comparisons of the Optimism Scale to well-established measures of optimism, such as the LOT and the LOT-R, would allow for the testing of incremental validity.

Optimism is an individual difference variable that plays an important role in life, because it is associated with factors that can influence our life positively or negatively (e.g., Carver \& Scheier, 2014; He et al., 2013; Hirsch et al., 2007). The present research provided a validation for the Optimism Scale in both in the United Kingdom and in Brazil. The measure focuses on the dispositional style of the construct, and the results provided strong psychometric evidence for its use, suggesting that the scale is an important tool to assess the topic, which may benefit future research. 


\section{References}

Alarcon, G. M., Bowling, N. A., \& Khazon, S. (2013). Great expectations: A metaanalytic examination of optimism and hope. Personality and Individual Differences, 54, 821-827.

Bandeira, M., Bekou, V., Lott, K. S., Teixeira, M. A., \& Rocha, S. S. (2002). Transcultural validation of the Life Orientation Test (LOT-R). Estudos de Psicologia (Natal), 7(2), 251-258. https://doi.org/10.1590/S1413294X2002000200006

Bastianello, M. R., \& Hutz, C. S. (2015). Do otimismo explicativo ao disposicional: a perspectiva da psicologia positiva. Psico-USF, 20, 237-247.

Carver, C. S. (2014). Self-control and optimism are distinct and complementary strengths. Personality and Individual Differences, 66, 24-26. https://doi.org/10.1016/j.paid.2014.02.041

Carver, C. S., \& Scheier, M. F. (2003). Optimism. In J. L. Shane \& C. R. Snyder, Positive psychology assessment: A handbook of models and measures (pp 75-89). Washington, DC: American Psychological Association

Carver, C. S., \& Scheier, M. F. (2014). Dispositional optimism. Trends in cognitive sciences, 18, 293-299.

Carver, C. S., Scheier, M. F., \& Segerstrom, S. C. (2010). Optimism. Clinical Psychology Review, 30(7), 879-889. https://doi.org/10.1016/j.cpr.2010.01.006

Chalmers, R. P. (2012). mirt: A Multidimensional Item Response Theory Package for the R Environment. Journal of Statistical Software, 48(6), 1-29.

Chang, E. C., D'Zurilla, T. J., \& Maydeu-Olivares, A. (1994). Assessing the dimensionality of optimism and pessimism using a multimeasure approach. 
Cognitive Therapy and Research, 18(2), 143-160.

https://doi.org/10.1007/BF02357221

Chen, F. F. (2007). Sensitivity of Goodness of Fit Indexes to Lack of Measurement Invariance. Structural Equation Modeling: A Multidisciplinary Journal, 14(3), 464-504. http://doi.org/10.1080/10705510701301834

Cheung, G. W., \& Rensvold, R. B. (2002). Evaluating Goodness-of-Fit Indexes for Testing Measurement Invariance. Structural Equation Modeling: A Multidisciplinary Journal, 9(2), 233-255. http://doi.org/10.1207/S15328007SEM0902_5

Chiesi, F., Galli, S., Primi, C., Innocenti Borgi, P., \& Bonacchi, A. (2013). The accuracy of the Life Orientation Test-Revised (LOT-R) in measuring dispositional optimism: evidence from item response theory analyses. Journal of Personality Assessment, 95(5), 523-529.

https://doi.org/10.1080/00223891.2013.781029

Cohen, J. (1992). A power primer. Psychological Bulletin, 112(1), 155-159.

Fernández-Berrocal, P., Extremera, N., \& Ramos, N. (2004). Validity and reliability of the Spanish modified version of the Trait Meta-Mood Scale. Psychological Reports, 94, 751-755.

Gaspar, T., Ribeiro, J. L. P., Matos, M. G., Leal, I., \& Ferreira, A. (2009). Optimismo em crianças e adolescentes: Adaptação e validação do LOT-R. Psicologia: Reflexão e Crítica, 22(3), 439-446.

Giltay, E. J., Geleijnse, J. M., Zitman, F. G., Buijsse, B., \& Kromhout, D. (2007). Lifestyle and dietary correlates of dispositional optimism in men: The Zutphen Elderly Study. Journal of Psychosomatic Research, 63(5), 483-490. https://doi.org/10.1016/j.jpsychores.2007.07.014 
Glaesmer, H., Rief, W., Martin, A., Mewes, R., Brähler, E., Zenger, M., \& Hinz, A. (2012). Psychometric properties and population-based norms of the Life Orientation Test Revised (LOT-R). British Journal of Health Psychology, 17(2), 432-445. https://doi.org/10.1111/j.2044-8287.2011.02046.x

Hair, J. F. J., Black, W. C., Babin, B. J., \& Anderson, R. E. (2015). Multivariate Data Analysis (7 edition). Upper Saddle River, NJ: Prentice Hall.

Hanel, P. H. P., \& Vione, K. C. (2016). Do student samples provide an accurate estimate of the general public? PLOS ONE, 11(12), https://doi.org/10.1371/journal.pone.0168354.

He, F., Cao, R., Feng, Z., Guan, H., \& Peng, J. (2013). The Impacts of Dispositional Optimism and Psychological Resilience on the Subjective Well-Being of Burn Patients: A Structural Equation Modelling Analysis. PLOS ONE, 8(12), e82939. https://doi.org/10.1371/journal.pone.0082939

Herzberg, P. Y., Glaesmer, H., \& Hoyer, J. (2006). Separating optimism and pessimism: A robust psychometric analysis of the Revised Life Orientation Test (LOT-R). Psychological Assessment, 18(4), 433-438. https://doi.org/http://dx.doi.org/10.1037/1040-3590.18.4.433

Hirsch, J. K., Wolford, K., LaLonde, S. M., Brunk, L., \& Morris, A. P. (2007). Dispositional Optimism as a Moderator of the Relationship Between Negative Life Events and Suicide Ideation and Attempts. Cognitive Therapy and Research, 31(4), 533-546. https://doi.org/10.1007/s10608-007-9151-0

Jovanović, V., \& Gavrilov-Jerković, V. (2013). Dimensionality and Validity of the Serbian Version of the Life Orientation Test-Revised in a Sample of Youths. Journal of Happiness Studies, 14(3), 771-782. https://doi.org/10.1007/s10902-0129354-2 
Kam, C., \& Meyer, J. P. (2012). Do optimism and pessimism have different relationships with personality dimensions? A re-examination. Personality and Individual Differences, 52(2), 123-127.

Kirby, M. M., \& DiPaola, M. F. (2011). Academic optimism and community engagement in urban schools. Journal of Educational Administration, 49(5), 542-562. https://doi.org/10.1108/09578231111159539

Kline, P. (2013). Handbook of Psychological Testing. Routledge.

Kubzansky, L. D., Kubzansky, P. E., \& Maselko, J. (2004). Optimism and Pessimism in the Context of Health: Bipolar Opposites or Separate Constructs? Personality and Social Psychology Bulletin, 30(8), 943-956. https://doi.org/10.1177/0146167203262086

Lorenzo-Seva, U., \& Ferrando, P. J. (2013). FACTOR 9.2 A Comprehensive Program for Fitting Exploratory and Semiconfirmatory Factor Analysis and IRT Models. Applied Psychological Measurement, 37(6), 497-498. http://doi.org/10.1177/0146621613487794

Lorenzo-Seva, U., Timmerman, M. E., \& Kiers, H. A. L. (2011). The Hull Method for Selecting the Number of Common Factors. Multivariate Behavioral Research, 46(2), 340-364. http://doi.org/10.1080/00273171.2011.564527

Malhotra, N., \& Margalit, Y. (2014). Expectation Setting and Retrospective Voting. The Journal of Politics, 76(4), 1000-1016. https://doi.org/10.1017/S0022381614000577

Marshall, G. N., Wortman, C. B., Kusulas, J. W., Hervig, L. K., \& Vickers Jr, R. R. (1992). Distinguishing optimism from pessimism: Relations to fundamental dimensions of mood and personality. Journal of personality and social psychology, 62, 1067- 1074. 
McCrae, R. R., Costa, P. T., \& Martin, T. A. (2010). The NEO-PI-3: A more readable revised NEO Personality Inventory. Journal of Personality Assessment, 84(3), 261270. https://doi.org/10.1207/s15327752jpa8403_05

Milfont, T. L., \& Fischer, R. (2010). Testing measurement invariance across groups: Applications in cross-cultural research. International Journal of Psychological Research, 3(1), 111-130. http://doi.org/10.21500/20112084.857

Monzani, D., Steca, P., \& Greco, A. (2014). Brief report: Assessing dispositional optimism in adolescence - Factor structure and concurrent validity of the Life Orientation Test - Revised. Journal of Adolescence, 37(2), 97-101. https://doi.org/10.1016/j.adolescence.2013.11.006

Pedrosa, I., Celis-Atenas, K., Suárez-Álvarez, J., García-Cueto, E., \& Muñiz, J. (2015). Cuestionario para la evaluación del optimismo: Fiabilidad y evidencias de validez. Terapia Psicológica, 33(2), 127-138. http://doi.org/10.4067/S071848082015000200007

Perczek, R., Carver, C. S., Price, A. A., \& Pozo-Kaderman, C. (2000). Coping, mood, and aspects of personality in Spanish translation and evidence of convergence with English versions. Journal of Personality Assessment, 74(1), 63-87. https://doi.org/10.1207/S15327752JPA740105

Peterson, C. \& Steen, T. (2009). Optimistic explanatory style. In: Snyder C and Lopez S (eds) Oxford Handbook of Positive Psychology. New York: Oxford, pp. 313-321. R Development Core Team. (2015). R: A language and environment for statistical computing. Retrieved from https://cran.r-project.org/doc/manuals/fullrefman.pdf Rasmussen, H. N., Scheier, M. F., \& Greenhouse, J. B. (2009). Optimism and Physical Health: A Meta-analytic Review. Annals of Behavioral Medicine, 37(3), 239. https://doi.org/10.1007/s12160-009-9111-x 
Reilley, S., Geers, A., Lindsay, D., Deronde, L., \& Dember, W. (2005). Convergence and predictive validity in measures of optimism and pessimism: Sequencial studies. Current Psychology, 24, 43-59.

Robinson-Whelen, S., Kim, C., MacCallum, R. C., \& Kiecolt-Glaser, J. K. (1997). Distinguishing optimism from pessimism in older adults: is it more important to be optimistic or not to be pessimistic? Journal of Personality and Social Psychology, 73(6), 1345-1353.

Scheier, M. F., \& Carver, C. S. (1985). Optimism, coping, and health: Assessment and implication of generalized outcome expectancies. Health Psychology, 4, 219-247.

Scheier, M. F., Carver, C. S., \& Bridges, M. W. (1994). Distinguishing optimism from neuroticism (and trait anxiety, self-mastery, and self-esteem): a reevaluation of the Life Orientation Test. Journal of Personality and Social Psychology, 67(6), 10631078.

Schou, I., Ekeberg, Ø., Ruland, C. M., Sandvik, L., \& Kåresen, R. (2004). Pessimism as a predictor of emotional morbidity one year following breast cancer surgery. Psycho-Oncology, 13(5), 309-320. https://doi.org/10.1002/pon.747

Segerstrom, S. C., Evans, D. R., \& Eisenlohr-Moul, T. A. (2011). Optimism and pessimism dimensions in the Life Orientation Test-Revised: Method and meaning. Journal of Research in Personality, 45(1), 126-129. https://doi.org/10.1016/j.jrp.2010.11.007

Sharpe, J. P., Martin, N. R., \& Roth, K. A. (2011). Optimism and the Big Five factors of personality: Beyond Neuroticism and Extraversion. Personality and Individual Differences, 51(8), 946-951. http://doi.org/10.1016/j.paid.2011.07.033

Škerlavaj, M., \& Dimovski, V. (2009). Organizational Learning and Performance in Two National Cultures: A Multi-group Structural Equation Modeling Approach. In 
W. R. King (Ed.), Knowledge Management and Organizational Learning (pp. 321367). Springer US. Retrieved from http://link.springer.com/chapter/10.1007/978-14419-0011-1_19

Snyder, C. R., Lopez, S. J., \& Pedrotti, J. T. (2010). Positive Psychology: The Scientific and Practical Explorations of Human Strengths. SAGE Publications.

Tabachnick, B. G., \& Fidell, L. S. (2013). Using Multivariate Statistics (6 edition). Pearson.

Vandenberg, R. J., \& Lance, C. E. (2000). A review and synthesis of the measurement invariance literature: Suggestions, practices, and recommendations for organizational research. Organizational Research Methods, 3(1), 4-70. https://doi.org/10.1177/109442810031002

Vera-Villarroel, P., Urzúa, A., Beyle, C., Contreras, D., Lillo, S., Oyarzo, F., \& SanínPosada, A. (2017). Relación entre optimismo y salud bajo la influencia de las creencias religiosas en dos muestras latinoamericanas. Revista Latinoamericana de Psicología, 49(3), 213-221. https://doi.org/10.1016/j.rlp.2017.03.002

Vigil-Colet, A., Morales-Vives, F., Camps, E., Tous, J., \& Lorenzo-Seva, U. (2013).

Development and validation of the Overall Personality Assessment Scale (OPERAS). Psicothema, 25(1), 100-106.

https://doi.org/10.7334/psicothema2011.411

Webster, G. D., \& Jonason, P. K. (2013). Putting the "IRT' in 'Dirty"': Item response theory analyses of the Dark Triad Dirty Dozen—An efficient measure of narcissism, psychopathy, and Machiavellianism. Personality and Individual Differences, 54, 302-306. 